\title{
Periodontal Status and Oral Health-Related Quality of Life among Elderly attending Kantipur Dental College, Kathmandu, Nepal
}

\author{
Dr. Anju Khapung, ${ }^{1}$ Dr. G. Nagaraja Rao, ${ }^{1}$ Dr. Sujita Shrestha, ${ }^{1}$ Dr. Bhageshwar Dhami, ${ }^{2}$ Dr. Sujaya Gupta ${ }^{2}$ \\ ${ }^{1}$ Department of Community Dentistry, ${ }^{2}$ Department of Periodontics, Kantipur Dental College, Kathmandu, Nepal.
}

\begin{abstract}
Background: In elderly, poor oral health in the form of tooth loss, dental caries, periodontal disease and oral cancer affects physical and psychological aspect of life. Health is not only absence of disease but also psychological and social well-being. Thus, the assessment of disease by clinical examination as well as measurement of psychosocial impacts associated with disease are equally important.

Aim: To find the association between periodontal status and oral health-related quality of life among elderly attending Kantipur Dental College.

Materials and Methods: A cross-sectional study was carried out among 184 elderly patients attending Kantipur Dental College by convenient sampling method. Oral health-related quality of life was assessed by GOHAI. Periodontal status was assessed by using CPI modified and Loss of attachment. Data was analysed with SPSS version 20.

Results: Among 184 total participants (74 men, 110 women), the mean GOHAI score was $46.59+8.70$. Of the total, 13\% had high GOHAI score whereas $27 \%$ had moderate and $60 \%$ had low GOHAI score. Periodontal status of elderly population was found to be significantly associated with oral health-related quality of life $(p<0.05)$.

Conclusion: The findings of this study suggest a need to improve oral health care and knowledge for elderly group through preventive and curative public health measures.

Keywords: Community periodontal index; elderly; geriatric oral health assessment index; oral health-related quality of life; periodontal status.
\end{abstract}

\section{INTRODUCTION}

Nepal Senior Citizens Act 2006 defines elderly as the individuals over the age of 60 years. ${ }^{1}$ Globally, there has been an increase in life expectancy due to declining mortality, advances in medicine and public health interventions. ${ }^{2}$ The elderly population percentage in Nepal has increased from 6.5\% (1.5 million) in 2001 to 8.13\% (2.1million) in 2011.3.4

Poor oral health among older people is manifested as tooth loss, dental caries, periodontal diseases and oral cancer. ${ }^{5}$ Oral health status affects individuals' physical and psychological

\section{Correspondence:}

Dr Anju Khapung

Department of Community Dentistry,

Kantipur Dental College, Kathmandu, Nepal.

email:saamik.2002@gmail.com

\section{Citation}

Khapung A, Rao GN, Shrestha S, Dhami B, Gupta S. Periodontal status and oral health-related quality of life among elderly attending Kantipur dental college, Nepal. J Nepal Soc Perio Oral Implantol. 2017;1(2):46-50. aspect of life as well as their appearance, speech, chewing ability, taste of food and socialisation. ${ }^{6}$

The traditional methods of oral health assessment are limited to recording of the clinical and oral indices and determining presence or absence of disease. But this does not make subjective measurements i.e. self-perception of oral health. ${ }^{7}$ Current concept of health suggests health as not only absence of disease but also physical, psychological and social well-being. ${ }^{8}$

Though there are many instruments to measure Oral HealthRelated Quality of Life (OHRQoL), the most preferred are Oral Health Impact Profile (OHIP-14) and Geriatric Oral Health Assessment Index (GOHAI) as they are short and do not pose significant burden to the respondents. However, GOHAI is the more sensitive measure of the two. ${ }^{9,10}$ Current published journals don't have any such study in context of Nepal. Hence, this study aims to find the periodontal status and OHRQoL among elderly patients attending Kantipur Dental College. 


\section{MATERIALS AND METHODS}

A cross-sectional study was carried out among 184 elderly patients attending Department of Oral Medicine and Radiology, Kantipur Dental College from $1^{\text {st }}$ July to $15^{\text {th }}$ August, 2017 by convenient sampling method. Sample size of 109 was calculated by:

$$
\mathrm{n}=\frac{\mathrm{N}}{1+\mathrm{Ne}^{2}}
$$

Where $\mathrm{n}=$ sample size

$\mathrm{N}$ = population size

$\mathrm{e}=$ margin of error $(0.05)$

For this study, people 60 years and above were considered as elderly. Elderly patients who were mentally not stable, not willing to participate or completely edentulous were excluded from the study.

Ethical approval was taken from Institutional Review Committee (IRC) of Kantipur Dental College, Teaching Hospital. Written informed consent was taken from all the study participants. Prior to the main study, a pilot study was done among 20 elderly patients attending dental OPD of Kantipur Dental College. These patients were not included in the main study. Reliability of GOHAI was measured by Cronbach's alpha (0.79). Validity of GOHAI was checked by back translation method. GOHAI was translated into Nepali by two dentists. The Nepali version was then back-translated into English by two other dentists. The back-translated version was then compared with the original English version and verified by experts. Intra examiner reliability was measured by Kappa coefficient. Kappa value for bleeding, pocket and loss of attachment were $0.89,0.92$ and 0.9 respectively.

Data collection was done by using proforma which consisted of three parts. First part included socio-demographic characteristics, second part included a tool to assess OHRQoL and third part included clinical examination. OHRQoL was assessed by a Nepali version of GOHAI. Instruments used for clinical examination were mouth mirror and CPITN (Community Periodontal Index Treatment Needs) probe. Periodontal status was assessed by a single examiner using Community Periodontal Index (CPI) - modified and Loss of attachment (LOA).

GOHAI is a 12 item questionnaire, which was developed by Atchison and Dolan.11 It evaluates the patient's perception about effects of oral health problems on daily activities in the past three months. Participants can respond on a five point Likert scale $(5=$ never, $4=$ seldom, $3=$ sometimes, 2 = often, 1 = always). GOHAI score was obtained by summing the response codes after reversing the coding of 3 positively worded items. GOHAI score of $<50$ means 'low perception', 51-56 means 'moderate perception' and 57-60 means 'high perception' on oral health. CPI modified includes CPI bleeding and CPI pocket scores. CPI bleeding score records presence or absence of gingival bleeding on probing. CPI pocket score records presence or absence of periodontal pockets and various pocket depths. LOA score estimates lifetime accumulated destruction of the periodontal attachment.

Data was entered in Epidata version 3.1. Data analysis was done using SPSS version 20. Descriptive and inferential statistics were used. Association between GOHAI score and various socio-demographic variables was tested by MannWhitney U test and association between GOHAI score and periodontal status was tested by Kruskal-Wallis tests as the data was not normally distributed. $p<0.05$ was considered as statistically significant.

\section{RESULTS}

Socio-demographic characteristics: A total of 184 elderly were examined out of which 110 (60\%) were female and 74 (40\%) were male. Age-wise distribution of the participants showed that 113 (61.4\%) were in the 60-69 year age group, 55 (29.9\%) were in the $70-79$ year age group and 16 (8.7\%) were in the 80 years and older age group. Among study participants, 87 (47.3\%) did not have formal schooling, 61 (29.9\%) had completed school and 36 (8.7\%) had completed college education.

OHRQoL: The mean GOHAI score was $46.59 \pm 8.70$. Of the total, $13 \%$ had high GOHAI score whereas $27 \%$ had moderate and $60 \%$ had low GOHAI score. The association between mean GOHAI scores and gender was not found to be statistically significant ( $p$ value $=0.121$ ). Similar finding was seen between mean GOHAI score and age category ( $p$ value $=0.093$ ). The mean GOHAI scores increased as per the education level of the participants and this was found to be statistically significant ( $p$ value $<0.005$ ).

Periodontal status: Among the total participants (Figure 1), 79 (42.9\%) participants had a score of 0 (absence of condition) as the highest CPI-Bleeding score, 71 (38.6\%) participants had a score of 1 (presence of condition) as the highest CPI-Bleeding score, 3 (1.6\%) participants were excluded and 31 (16.9\%) participants had score $\mathrm{X}$ (tooth not present) as the highest CPI-Bleeding score.

According to the highest CPI-Pocket score (Figure 2), 117 (63.6\%) participants had a score of 0 (absence of condition), 28 (15.2\%) participants had a score of 1 (pocket 4-5 mm), 3 (1.6\%) participants had a score of 2 (pocket $6 \mathrm{~mm}$ or more), 4 (2.2\%) participants were excluded and 32 (17.4\%) participants had score X (tooth not present).

According to highest LOA score (Figure 3), 75 (40.8\%) participants had a score of 0 (attachment loss 0-3 mm), 43 (23.4\%) participants had a score of 1 (attachment loss 4-5 mm), 27 (14.7\%) participants had a score of 2 (attachment loss 6-8 $\mathrm{mm}), 3$ (1.6\%) participants had a score of 3 (attachment loss 9-11 mm), 28 (15.2\%) participants were excluded and 8 (4.3\%) were not recorded. 
Figure 1: Age-wise distribution of study participants according to highest CPI- gingival bleeding score.

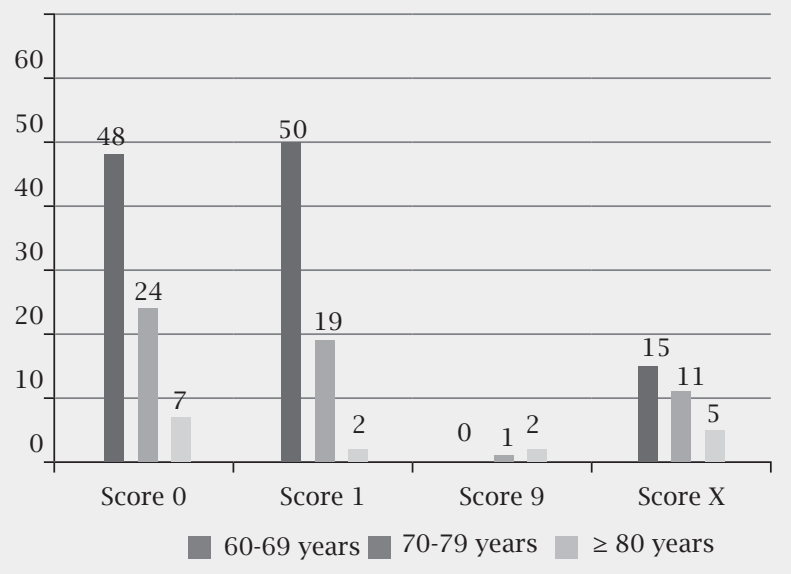

Figure 2: Age-wise distribution of study participants according to highest CPI- Pocket score.

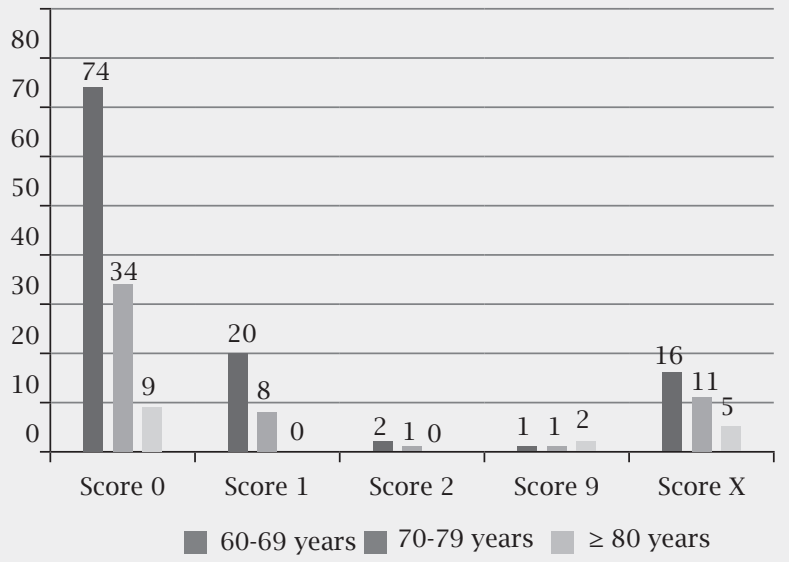

Figure 3: Age-wise distribution of study participants according to the highest Loss of Attachment score.

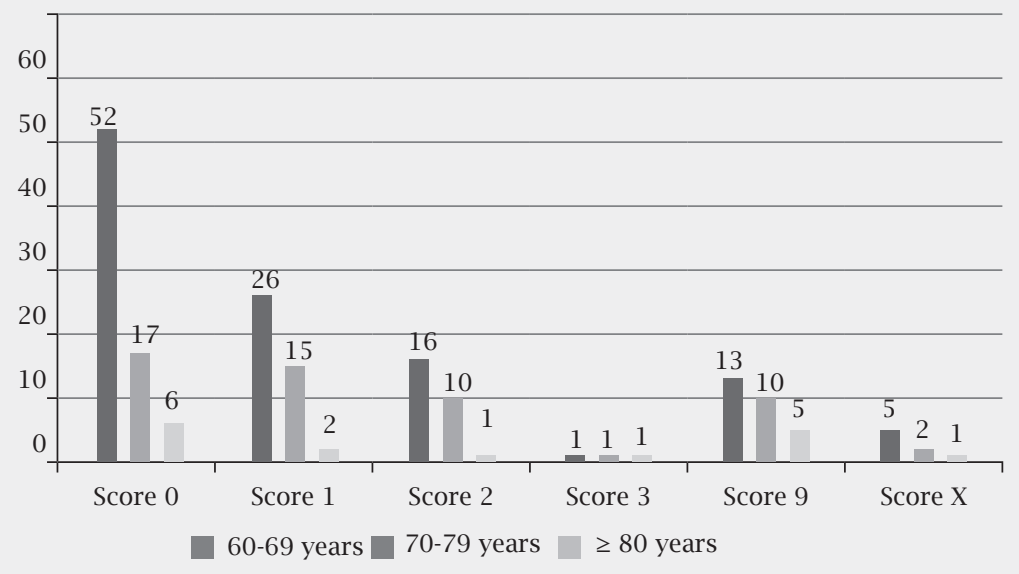

Relationship between OHRQoL and periodontal status: Mean GOHAI scores showed a statistically significant decrease with increase in CPI-Bleeding scores and also with increase in CPIPocket scores (Table 1).
The mean GOHAI scores showed a decrease with an increase in LOA scores and this difference was found to be statistically significant (Table 2).

Table 1: Comparison of CPI-modified scores and mean GOHAI score.

\begin{tabular}{|c|c|c|c|}
\hline & Mean GOHAI score (+SD) & Test Value & $p$ value \\
\hline \multicolumn{4}{|c|}{ CPI Gingival Bleeding score } \\
\hline Score 0 & $49.73(8.09)$ & \multirow{4}{*}{$23.55 \dagger$} & \multirow{4}{*}{$<0.001 *$} \\
\hline Score 1 & $45.59(8.18)$ & & \\
\hline Score 9 & $40.33(6.35)$ & & \\
\hline Score X & $41.45(8.59)$ & & \\
\hline \multicolumn{4}{|c|}{ CPI Pocket score } \\
\hline Score 0 & $48.54(8.56)$ & \multirow{5}{*}{$9.19 \dagger$} & \multirow{5}{*}{$0.027^{*}$} \\
\hline Score 1 & $45.25(6.56)$ & & \\
\hline Score 2 & $50.67(8.33)$ & & \\
\hline Score 9 & $39.5(5.45)$ & & \\
\hline Score X & $41.13(8.57)$ & & \\
\hline
\end{tabular}

*significant + Kruskal Wallis Chi square statistic 
Table 2: Comparison of LOA scores and mean GOHAI score.

\begin{tabular}{|c|c|c|c|}
\hline & Mean GOHAI score (+SD) & Test Value & $p$ value \\
\hline \multicolumn{4}{|c|}{ LOA score } \\
\hline Score 0 & $49.44(8.55)$ & \multirow{6}{*}{$16.54 \dagger$} & \multirow{6}{*}{$0.005 *$} \\
\hline Score 1 & $45.72(7.63)$ & & \\
\hline Score 2 & $45.04(8.27)$ & & \\
\hline Score 3 & $42(7.94)$ & & \\
\hline Score X & $42.18(9.35)$ & & \\
\hline Score 9 & $46.88(7.9)$ & & \\
\hline
\end{tabular}

\section{DISCUSSION}

Periodontal diseases are seen more in the elderly population due to the cumulative progression of disease over time. Poor periodontal status adversely affects oral health related quality of life.

In the present study, participants with no formal education showed lower mean GOHAI scores indicating poorer OHRQoL as compared to participants with any form of formal education and this difference was found to be statistically significant. This is in accordance with studies carried out by Atchison and Dolan, ${ }^{11}$ Rekhi A et al., ${ }^{12}$ and Tubert-Jeannin et al. ${ }^{13}$ who found similar results; that is people with higher education level tend to perceive less impact on their OHRQoL than with lower education level. This finding did not correlate with the study carried out by Ibeke et al. ${ }^{17}$ which showed that education level did not have significant relation with the GOHAI scores. Higher mean GOHAI scores in people with higher education level could be because they tend to be more concerned about their oral health and adopt healthy oral practices.

Age category was not significantly associated with GOHAI scores. This is in accordance to studies done by Alcarde et al., ${ }^{14}$ and Ibeke et al. ${ }^{17}$ which did not find any significant association between age category and GOHAI scores. In contrast, the studies done by Raja et al., ${ }^{15}$ and Rekhi et al. ${ }^{12}$ showed that there was a decline in mean GOHAI scores with increasing age. Non-association of age category with GOHAI scores seen in this study could be because of non-uniform distribution of study participants in various age groups.

There was no significant association between gender and GOHAI scores. This is in agreement with a study done by Ibeke et al. ${ }^{17}$ which showed that gender did not have a significant relation with GOHAI. In contrast, the studies done by Rekhi et al., ${ }^{12}$ and Atieh ${ }^{16}$ found that women showed lower mean
GOHAI scores as compared with men. This could be because the majority of participants in this study were female.

Relationship between GOHAI scores and CPI scores showed that with an increase in CPI score, a significant decrease in mean GOHAI score was observed. Contradictory results were seen in a study carried out by Wong et al. ${ }^{18}$ who found no significant association between the two variables.

There was a significant association between GOHAI scores and LOA scores. Participants with higher LOA scores had lower GOHAI scores. This is in accordance to a study carried out by Rekhi et al. ${ }^{12}$ which showed that participants with greater LOA scores reported poor OHRQoL.

Current study is the first of its kind in the context of Nepal. However, the study participants included only those elderly patients attending a single dental hospital. So it may not represent the general population.

\section{CONCLUSION}

This study showed that majority of participants had low perception on oral health which indicated poor quality of life due to oral health problems. This finding suggests the need to improve oral health care and knowledge for elderly group through preventive and curative public health measures. So further research with larger sample size and in different settings could be done to generalize the results and plan for necessary public health interventions accordingly.

\section{ACKNOWLEDGEMENT}

We would like to thank Dr. Rosina Bhattarai and Dr. Sunita Khanal, Department of Community Dentistry and all the staffs of Department of Oral Medicine and Radiology, Kantipur Dental College, Kathmandu, Nepal for their guidance and support. 


\section{REFERENCES}

1. Act SC. 2063 (2006). Kathmandu, Nepal: Nepal Law Commission. 2006.

2. Shrestha L. Geriatric health in Nepal: Concerns and experience. Nepal Med Coll J. 2012;15(2):144-8.

3. Central Bureau of Statistics. Population Census 2001, National Report. Kathmandu: His Majesty's Government National Planning Commission Secretariat; 2002.

4. Central Bureau of Statistics. Population Census 2011, National Report. Kathmandu: His Majesty’s Government National Planning Commission Secretariat; 2012.

5. Petersen P, Kandelman D, Arpin S, Ogawa H. Global oral health of older people-call for public health action. Community Dent Health. 2010;27(4).

6. Sheiham A, Steele JG, Marcenes W, Tsakos G, Finch S, Walls AW. Prevalence of impacts of dental and oral disorders and their effects on eating among older people; a national survey in Great Britain. Community Dent Oral Epidemiol. 2001; 29(3):195-203.

7. Sánchez-García S, Heredia-Ponce E, Juárez-Cedillo T, Gallegos-Carrillo K, Espinel-Bermúdez C, La Fuente-Hernández D, et al. Psychometric properties of the General Oral Health Assessment Index (GOHAI) and dental status of an elderly Mexican population. J Public Health Dent. 2010;70(4):300-7.

8. Inglehart MR, Bagramian RA, editors. Oral health-related quality of life. Chicago: Quintessence Publising Co., Inc.; 2002.

9. Ikebe K, Hazeyama T, Enoki K, Murai S, Okada T, Kagawa R, et al. Comparison of GOHAI and OHIP-14 measures in relation to objective values of oral function in elderly Japanese. Community Dent Oral Epidemiol. 2012;40(5):406-14.

10. Locker D, Matear D, Stephens M, Lawrence H, Payne B. Comparison of the GOHAI and OHIP-14 as measures of the oral health-related quality of life of the elderly. Community Dent Oral Epidemiol. 2001;29(5):373-81.

11. Atchison KA, Dolan TA. Development of the Geriatric Oral Health Assessment Index. J Dent Educ. 1990;54(11):680-7.

12. Rekhi A, Marya CM, Oberoi SS, Nagpal R, Dhingra C, Kataria S. Periodontal status and oral health $\square$ related quality of life in elderly residents of aged care homes in Delhi. Geriatr Gerontol Int. 2016 Apr;16(4);474-80.

13. Tubert-Jeannin S, Riordan PJ, Morel-Papernot A, Porcheray S, Saby Collet S. Validation of an oral health quality of life index (GOHAI) in France. Community Dent Oral Epidemiol 2003;31:275-84.

14. Alcarde AC, Bittar TO, Fornazari DH, Meneghim MC, Ambrosano GM, Pereira AC. A cross-sectional study of oral health-related quality of life of Piracicaba's elderly population. Rev Odonto Cienc. 2010;25:126-31.

15. Raja BK, Radha G, Rekha R, Pallavi SK. Relationship between the sense of coherence and quality of life among institutionalized elders in Bengaluru city India: A questionnaire study. J Indian Assoc Public Health Dent. 2015;13:479-85.

16. Atieh MA. Arabic version of the geriatric oral health assessment index. Gerodontology. 2008 Mar;25(1):34-41.

17. Ikebe K, Hazeyama T, Enoki K, Murai S, Okada T, Kagawa R, Matsuda KI, Maeda Y. Comparison of GOHAI and OHIP-14 measures in relation to objective values of oral function in elderly Japanese. Community Dent Oral Epidemiol. 2012 Oct;40(5):406-14.

18. Wong MC, Liu JK, Lo EC. Translation and validation of the Chinese version of GOHAI. J Public Health Dent. 2002 Spring;62(2):78-83. 